\title{
¿Response of Regional Asian Summer Monsoons to the Effect of Reduced Surface Albedo in Different Tibetan Plateau Domains in Idealized Model Experiments
}

\author{
Mengmeng Lu, ${ }^{\mathrm{a}, \mathrm{b}}$ SONG YAnG,,${ }^{\mathrm{a}, \mathrm{b}, \mathrm{c}}$ Junbin WAng, ${ }^{\mathrm{a}, \mathrm{b}}$ Yuting Wu, ${ }^{\mathrm{a}, \mathrm{b}}$ AND XiAOlOnG JiA ${ }^{\mathrm{d}}$ \\ ${ }^{a}$ School of Atmospheric Sciences, Sun Yat-sen University, Zhuhai, China \\ ${ }^{\mathrm{b}}$ Southern Marine Science and Engineering Guangdong Laboratory (Zhuhai), Zhuhai, China \\ ${ }^{\mathrm{c}}$ Guangdong Province Key Laboratory for Climate Change and Natural Disaster Studies, \\ Sun Yat-sen University, Zhuhai, China \\ ${ }^{\mathrm{d}}$ National Climate Center, China Meteorological Administration, Beijing, China
}

(Manuscript received 30 June 2020, in final form 25 May 2021)

\begin{abstract}
The thermal effect of the entire Tibetan Plateau (TP) tends to strengthen the South Asian summer monsoon (SASM); however, how does this monsoon component respond to the thermal conditions of different TP domains? How do the thermal conditions of the entire TP influence other monsoons, including the East Asian summer monsoon (EASM) and the Southeast Asian summer monsoon (SEASM)? These questions are addressed by conducting an experiment with the CESM, which is forced by reducing the surface albedo over the plateau by half, from a TP-averaged 0.20 to 0.10, from May to September, and similar experiments for different TP domains. Both observational and model results show that the entire TP heating intensifies the large-scale Asian monsoon, the SASM, and the EASM but surprisingly weakens the SEASM. It is also surprising that the TP heating exerts a stronger effect on the EASM than on the SASM. The southern TP (south of $35^{\circ} \mathrm{N}$ ) does not show the strongest impact on the SASM in comparison with other TP domains, and it exerts the weakest impact on the EASM, which is most strongly influenced by the thermal effect of the eastern (east of $90^{\circ} \mathrm{E}$ ) and northern TP. The western TP weakens the SEASM (as do the other domains), and it strengthens other monsoon components. The thermal conditions of the southern and eastern TP are accompanied by signals of tropical atmospheric response at relatively broader spatial scales, whereas those of the northern TP more apparently lead to a significant wave train extending eastward from the TP to western Eurasia over the higher latitudes.
\end{abstract}

KEYWORDS: Topographic effects; Monsoons; Climate variability

\section{Introduction}

Large-scale orography plays a crucial role in influencing atmospheric circulation through both dynamic and thermodynamic effects. As the highest plateau in the world, the Tibetan Plateau (TP), with an average elevation of terrain of $4500 \mathrm{~m}$, influences the Asian monsoon and even the climate over much of the world significantly (e.g., Flohn 1957; Yeh et al. 1957; Hahn and Manabe 1975; Ye and Wu 1998; Kitoh 2004; Liu et al. 2007; Wu et al. 2009; Boos and Kuang 2010, 2013; Ma et al. 2014; Wu et al. 2016; Lu et al. 2018; Liu et al. 2020). Studies have claimed that sensible heating over the TP, especially its southern sloping surface, is the major driving force to transport abundant moisture from oceans to land, leading to increased monsoonal rainfall over the Asian continent (Wu et al. 1997, 2007). According to the land-atmosphere interaction concept of Webster (1983), surface sensible heating resulting from solar radiation is essential for the subsequent

¿ Denotes content that is immediately available upon publication as open access.

Additional affiliation for Lu: Department of Earth and Planetary Sciences, Harvard University, Cambridge, Massachusetts.

Corresponding author: Song Yang, yangsong3@mail.sysu.edu.cn occurrence of low-level cyclonic monsoonal circulation and convergence, rising motion, and monsoon rainfall. Recently, Wu et al. (2020) applied an advanced dynamical diagnostic tool to confirm the importance of sensible heating relative to other dynamic and radiative processes for the change in TP temperature.

The thermal effect of TP is widely believed to be important for the multiple time-scale variations of the Asian summer monsoon system including the South Asian summer monsoon (SASM) and the East Asian summer monsoon (EASM). Wu et al. (2015) discussed the importance of the plateau for the formation of monsoon from the perspective of the water vapor belt over South Asia, which can be separated into three major branches. The first branch, the southern band of SASM, extends from the Arabian Sea and the Bay of Bengal to the South China Sea (SCS) and induces heavy precipitation due mainly to the land-sea thermal contrast. The second branch, the northern band of SASM, extends northward across northern India and the Bay of Bengal toward the southern slope of TP. The third branch transports water vapor to sustain the EASM owing to the thermal effects of both the land-sea contrast and the TP.

The TP affects the formation of monsoon or the timing of monsoon onset (e.g., Luo and Yanai 1983, 1984; He et al. 1987; Lau and Yang 1996; Ueda and Yasunari 1998; Wu and Zhang 1998; Abe et al. 2013) and the mean intensity of monsoon (Hsu and Liu 2003; Wang et al. 2008a; Duan et al. 2011, 2013; Wang et al. 2014). Based on 40-day observational data from 
late May to early July 1979, Luo and Yanai (1983, 1984) demonstrated the profound orographic effect of TP on Asian monsoon evolution. The authors carefully analyzed the variations of apparent heat source (Q1) and apparent moisture sink (Q2) associated with monsoon evolution and revealed their difference between eastern and western TP regions. Abe et al. (2013) discussed the influence of the TP on the onset of Asian summer monsoon via air-sea interaction over the Indian Ocean during the premonsoon season.

The mountain uplift effect of the TP is important for the Asian monsoon and its different impacts on various monsoon components measured by area-mean rainfall (Abe et al. 2003). While the mountain lift effect enhances the Indian monsoon apparently, especially in the monsoon's later stage, it strengthens the East Asian monsoon at its earlier stage more effectively. Kitoh (2004) further investigated the impact of mountain uplift by examining large-scale patterns, with a focus on the effect on East Asian monsoon, and indicated that the mountain uplift effect was stronger in an atmosphere-ocean coupled model when compared with an atmosphere-alone model. Wang et al. (2008a) demonstrated that TP warming increases the subtropical frontal rainfall over East Asia through the linkage between two Rossby wave trains and the isentropic uplift to the east of TP, which deform the western Pacific subtropical high (WPSH) and enhance moisture convergence toward the subtropical front.

Global warming causes changes in the TP and monsoons, especially the Asian monsoons (Li et al. 2010; Kitoh et al. 2013; $\mathrm{Wu}$ et al. 2020). The global monsoon precipitation increases because of strengthening moisture convergence due to enhancement of surface evaporation and air-column water vapor (Kitoh et al. 2013). Analysis of the results from 30 CMIP5 modes based on global warming scenarios further shows that the change in land-sea thermal contrast cannot explain the enhanced EASM circulation (C. He et al. 2019). Instead, the enhanced low-level southerly wind over East Asia is associated with an anomalous cyclone around the TP, and the intensified TP latent heating is responsible for this lower-level cyclonic anomaly and thus the projected enhanced EASM circulation.

Despite the recent advances in understanding the climate impact of TP, many features about the TP's effect on the Asian summer monsoon remain unclear. Although TP heating enhances the Asian monsoon overall, does it affect all the regional monsoon components in the same way? In this context, little is known about the TP effect on the Southeast Asian summer monsoon (SEASM), given that monsoon behaves remarkably differently in South Asia, East Asia, and Southeast Asia (Lau et al. 2000; Yoo et al. 2006). Second, although the southern slope of the TP has been claimed to be important for influencing the SASM (Wu et al. 2015), how does this influence compare with the impact of other TP domains and how does it compare with its effects on other monsoon components? The main objective of this study is to understand how the TP and its different domains influence the various regional components of the Asian summer monsoon system. Within this context, we will discuss the relative importance of the wet and convective conditions of the southeastern TP and the dry and less convective conditions of western and northern TP for monsoon variations. We will also discuss the relative importance of the divergent and rotational effects of the tropical and extratropical portions of the TP for the variations of monsoon circulation. It should also be pointed out that the current study is focused on the change in the mean intensity of summer monsoons, without addressing the features of the seasonal evolutions of monsoons.

The paper is organized as follows. In section 2, the data, model and experiments, and analysis methods are discussed. Section 3 demonstrates the thermal effects of TP and its various domains on various regional monsoon systems and depicts the related physical processes. Conclusions and a further discussion are given in section 4 .

\section{Data, model experiments, and analysis methods}

\section{a. Data, model, and experiment design}

The ERA-Interim reanalysis data from the European Centre for Medium-Range Weather Forecasts with a spatial resolution of $1^{\circ} \times 1^{\circ}$ (Dee et al. 2011) are used in this study. Specifically, the temperature, geopotential height, and wind fields for the period of 1979-2016 are analyzed.

The study also applies the NCAR Community Earth System Model, version 1.2.2 (CESM 1.2.2), a state-of-the-art global climate model (Neale et al. 2013), to carry out several experiments to understand the TP impact on monsoon. The fully coupled model has a resolution of $1.9^{\circ}$ in latitude and $2.5^{\circ}$ in longitude, with 26 vertical levels for the atmosphere and approximately $1^{\circ}$ for oceans. The values of solar forcing, ozone concentration, carbon dioxide, and aerosol are fixed at the level of year 2000 in all of the experiments.

Our model experiments are fully coupled simulations. As in $\mathrm{Lu}$ et al. (2018), the control run CTRL is integrated for 300 years, with output from years 261-300 analyzed. To understand the climate effect of entire TP, a sensitivity experiment TP_Alb05 is restarted from year 251 of CTRL and integrated from year 251 to year 300, in which external forcing is the same as in CTRL but surface albedo in TP $\left(23^{\circ}-\right.$ $45^{\circ} \mathrm{N}, 62^{\circ}-105^{\circ} \mathrm{E}$, where topography is above $1500 \mathrm{~m}$ ) is reduced by one-half from May to September, as in $\mathrm{Lu}$ et al. (2018). More specifically, the TP-averaged surface albedo is reduced from 0.20 in the control experiment to 0.10 in experiment TP_Alb05.

To understand the impacts of the southern, northern, eastern, and western TP domains on monsoons, we further correspondingly conduct four sensitivity experiments SouthTP Alb05, NorthTP_Alb05, EastTP_Alb05, and WestTP_Alb05, in each of which surface albedo is reduced by half as in $\mathrm{TP}_{-}$ Alb05. Specifically, the domain-averaged albedo is changed from 0.18 in control run to 0.09 in sensitivity run for experiment SouthTP_Alb05, from 0.22 to 0.11 for NorthTP_Alb05, from 0.18 to 0.09 for EastTP_Alb05, and from 0.22 to 0.11 for WestTP_Alb05. In these experiments, the southern TP and the northern TP are divided by the latitude of $35^{\circ} \mathrm{N}$, and the eastern TP and the western TP are split by the longitude $90^{\circ} \mathrm{E}$, which is somewhat subjective but is based on careful 
considerations of the sizes of various TP domains and the resolutions of the model (the CESM). As for CTRL, outputs from years 261-300 are analyzed for all sensitivity experiments.

\section{b. Analysis methods}

As described above, we change the thermal forcing of the TP by modifying the surface albedo of the plateau. A reduction of surface albedo increases surface temperature due to enhancement in absorption of solar radiation. As a result, sensible heating increases, leading to rising motion and convergence of the moist lower atmosphere. The latent heating from condensation further heats the atmosphere. Indeed, the results from experiment TP_Alb05, when compared with control run CTRL, indicate that when albedo is reduced the total diabatic heating and its various components including sensible heating, latent heating, and the net radiative heating all increase (figure not given). Particularly, sensible heating seems to contribute most to the total diabatic heating. This result is consistent with that of Wu et al. (2020), who applied an advanced dynamical diagnostic tool, the coupled surface air feedback response analysis method by Cai and Lu (2009) and $\mathrm{Lu}$ and Cai (2009), to attribute temperature changes to different contributing processes and demonstrated that the increase in summer temperature over the TP was positively and most dominantly contributed by albedo and sensible heating effects, but negatively and weakly by cloud feedback [see Fig. 3 in $\mathrm{Wu}$ et al. (2020)]. Lu et al. (2018) also found that the TP thermal impacts with varied values of surface albedo reduction were capable of leading to enhanced diabatic heating from the lower troposphere to the upper troposphere, increasing atmospheric temperature, and affecting large-scale atmospheric circulation. For this reason, TP heating and TP warming are used alternately in this study.

We assess the changes in various monsoon components by examining the changes in various fields of winds, geopotential height, and rainfall mainly from the differences between various model experiments. Several commonly used dynamical monsoon indices defined by atmospheric circulation field and their associated features are analyzed to measure the changes in the Asian summer monsoon and its different components.

The large-scale Asian monsoon is measured by the Webster and Yang (1992) monsoon index (herein called the W-Y index), which is defined as the vertical shear between 850- (U850) and $200-\mathrm{hPa}$ (U200) zonal winds averaged over $0^{\circ}-20^{\circ} \mathrm{N}$, $40^{\circ}-110^{\circ} \mathrm{E}$. A higher value of the index depicts a larger meridional thermal gradient over Asia and the northern Indian Ocean, and thus a stronger large-scale Asian monsoon circulation, although it may not be necessarily related to all regional monsoon components uniformly and strongly.

The SASM index (Goswami et al. 1999) is defined as the vertical shear between 850 - and $200-\mathrm{hPa}$ meridional winds averaged over $10^{\circ}-30^{\circ} \mathrm{N}, 70^{\circ}-110^{\circ} \mathrm{E}$. An above-normal SASM index value indicates a stronger meridional-vertical cell and thus a stronger monsoon circulation over South Asia.

The EASM index (Lau et al. 2000) is defined as the horizontal shear of $200-\mathrm{hPa}$ zonal winds between $40^{\circ}-50^{\circ} \mathrm{N}, 110^{\circ}-$ $150^{\circ} \mathrm{E}$ and $25^{\circ}-35^{\circ} \mathrm{N}, 110^{\circ}-150^{\circ} \mathrm{E}$. This index is designed to measure the meridional shift of the upper-tropospheric westerly jet stream over East Asia, which signifies how far the lower-tropospheric monsoon flow extends northward. Here, both upper- and lower-tropospheric monsoon flows usually extend more northward, meaning a stronger monsoon, when EASM is larger.

The SEASM index (Wang and Fan 1999) is defined as the horizontal shear of $850-\mathrm{hPa}$ zonal winds between $5^{\circ}-15^{\circ} \mathrm{N}$, $90^{\circ}-130^{\circ} \mathrm{E}$ and $22.5^{\circ}-32.5^{\circ} \mathrm{N}, 110^{\circ}-140^{\circ} \mathrm{E}$. That is, this index measures the change in the relative vorticity of the lower troposphere. A higher index value (representing a stronger monsoon) indicates larger vorticity, accompanied with a weaker condition of the western portion of the WPSH over Southeast Asia.

As compared with monsoon rainfall indices, these dynamical indices facilitate our analysis of the physical processes of monsoon and thus are better for improving our understanding of monsoon dynamics. As seen from the next section, several other monsoon indices are also employed as supplementary materials to demonstrate the robustness of the features obtained or enhance the discussions of those features.

\section{Results}

\section{a. Major features of TP impact on regional monsoons}

Previous studies (Liu and Yanai 2001; Nan et al. 2009; Zhao et al. 2010, 2011, 2012; Zuo et al. 2012, 2013; Jiang et al. 2013a) have shown a highly positive relationship between surface temperature and tropospheric temperature, here the vertically integrated temperature from $500 \mathrm{hPa}(700 \mathrm{hPa}$ if topography is below $3000 \mathrm{~m}$ ) to $200 \mathrm{hPa}$, owing to the hydrostatic characteristics of the atmosphere. Increases in tropospheric temperature can be induced by the increase in regional heat transfer from the surface to the atmosphere (Zhao et al. 2012). It has also been demonstrated that TP tropospheric temperature (TPTT) more appropriately measures the large-scale heating inside the atmosphere in comparison with the relatively noisy distribution of surface temperature and thus more effectively deciphers the remote climate impact of TP thermal effect (e.g., Jiang et al. 2013a). Figure 1a shows significant year-to-year variation of detrended June-August (JJA) TPTT for $1979-2016$, averaged over $23^{\circ}-45^{\circ} \mathrm{N}, 62^{\circ}-105^{\circ} \mathrm{E}$ where topography is above $1500 \mathrm{~m}$. From the time series, high-value years $(1981,1984,1998,2006,2013$, and 2016) and low-value years $(1983,1989,1992,1993,1997,2004,2009$, and 2015) are selected using the criterion of 1 standard deviation (both positive and negative) for a composite analysis. We point out that these selected summers are not ENSO summers except the moderately high Niño-3.4 index values of 1.6 and 1.5 in the summers of 1997 and 2015. The TPTT is naturally related with the tropospheric temperature over TP uniformly and significantly, but the most significant relationship appears over the central-northern plateau (Fig. 1b). The TPTT index is also significantly linked to the pattern of surface air temperature, especially over the eastern TP (Fig. 1c). In particular, the correlation between TPTT and the corresponding surface temperature index averaged in the 
(a) Time Series of TPTT (Trend Removed)

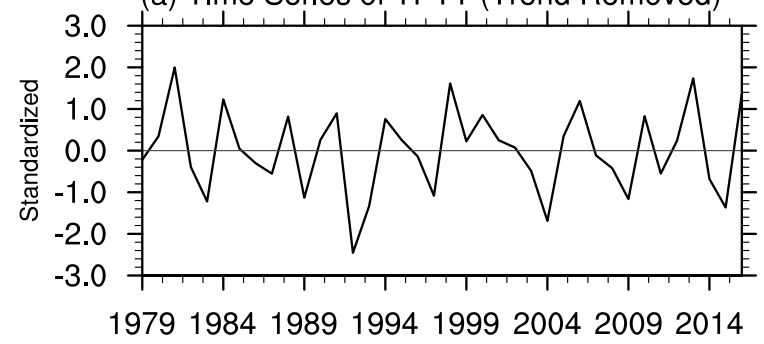

(b) Diff. in TT (Pos TPTT - Neg TPTT) JJA

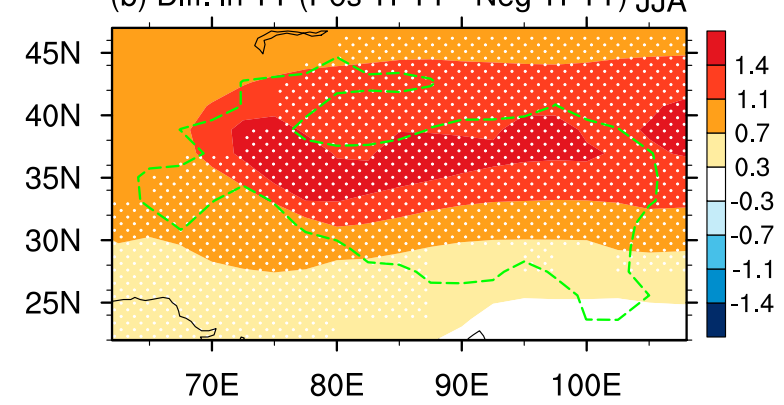

(c) Diff. in Ts (Pos TPTT - Neg TPTT) JJA

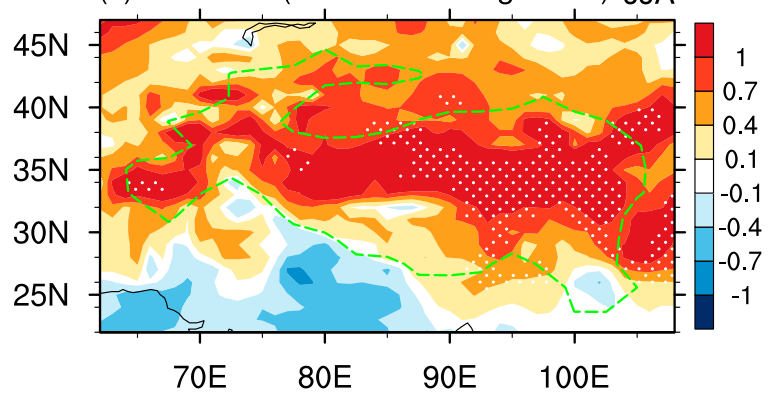

FIG. 1. (a) Time series of JJA tropospheric temperature, the integrated temperature from $500 \mathrm{hPa}(700 \mathrm{hPa}$ if topography is below $3000 \mathrm{~m})$ to $200 \mathrm{hPa}$, over the TP $\left(23^{\circ}-45^{\circ} \mathrm{N}, 62^{\circ}-105^{\circ} \mathrm{E}\right.$ where the topography is above $1500 \mathrm{~m}$ ) with its linear trend removed, referred to as TPTT, and composite patterns of difference in (b) tropospheric temperature (shading; ${ }^{\circ} \mathrm{C}$ ) and (c) surface air temperature (shading; ${ }^{\circ} \mathrm{C}$ ) between high- and low-TPTT summers. White stippling indicates values above the $95 \%$ confidence level. The topography of TP above $1500 \mathrm{~m}$ is marked with the dashed green contour.

same domain as for TPTT is highly significant (correlation coefficient $R=0.85$ ).

Figure 2 presents the composite values of difference in various monsoon indices in observation between high-TPTT years and low-TPTT years. It reveals an important feature: an increase in TPTT is associated rationally with intensifications of the large-scale Asian summer monsoon (see the W-Y index) and the regional monsoons over South Asia and East Asia, but unexpectedly with a weak reduction of the monsoon over Southeast Asia. The TPTT is most strongly linked to the EASM (with a percentage change of $32.8 \%$ ), following by the SASM $(9.1 \%)$, instead of the opposite as one may expect. The figure also indicates another important feature: the CESM sensitivity experiment with reduced surface albedo and thus

\begin{tabular}{|c|c|c|c|c|}
\hline & W-Y & SASM & EASM & SEASM \\
\hline \multirow{2}{*}{ OBS } & 1.55 & 0.31 & 4.09 & -0.22 \\
& $(5.8)$ & $(9.1)$ & $(32.8)$ & $(5.2)$ \\
\hline \multirow{2}{*}{ CESM } & 1.19 & 0.60 & 2.56 & -0.11 \\
& $(5.1)$ & $(17.0)$ & $(21.3)$ & $(1.7)$ \\
\hline
\end{tabular}

FIG. 2. Composite differences in various monsoon indices between observed high- and low-TPTT summers (observations, marked as OBS), and those between the TP heating sensitivity experiment and control experiment (marked as CESM). The values in parentheses represent the percentage (\%) change of the individual monsoon indices relative to the climatological means of observation or the model control experiment.

enhanced TPTT successfully mirrors the observed features (i.e., weakening of the SEASM and strengthening of the other monsoon components), with a strongest relation for the EASM. The previously unrecognized unique impact of TP on the SEASM, although quite small, will be discussed later.

Figure 3 further demonstrates the different impacts of different TP domains on the various regional Asian summer monsoons. The increases in heating over all TP domains generally strengthen the large-scale monsoon (W-Y index), the SASM, and the EASM, except the slightly negative impacts of the northern TP on the large-scale monsoon, and of the

\begin{tabular}{|l|c|c|}
\hline (a) & $\mathbf{W}-\mathbf{Y}$ & \\
\hline & -0.11 & \\
& $(0.5)$ & \\
\hline 0.20 & 23.46 & 0.44 \\
\hline$(0.9)$ & $(1.9)$ \\
\hline & 0.89 & \\
& $(3.8)$ & \\
\hline
\end{tabular}

\begin{tabular}{|c|c|c|}
\hline (c) & EASM & \\
\hline & $\begin{array}{l}0.94 \\
(7.8)\end{array}$ & \\
\hline $\begin{array}{l}0.67 \\
(5.6)\end{array}$ & 12.04 & $\begin{array}{c}2.93 \\
(24.3)\end{array}$ \\
\hline & $\begin{array}{c}-0.05 \\
(0.4)\end{array}$ & \\
\hline
\end{tabular}

\begin{tabular}{|c|c|c|c|c|c|}
\hline (b) & SASM & & (d) & \multicolumn{3}{|c|}{ SEASM } \\
\hline & 0.31 & & & -1.09 & \\
& $(8.8)$ & & & $(17.1)$ & \\
\hline 0.45 & & 0.29 & -1.00 & 6.37 & -0.80 \\
\hline$(12.7)$ & 3.54 & $(8.2)$ & $(15.7)$ & & $(12.6)$ \\
\hline & 0.28 & & & -0.68 & \\
& $(7.9)$ & & & $(10.7)$ & \\
\hline
\end{tabular}

FIG. 3. Differences in monsoon indices between regional TP sensitivity experiments and the control experiment. For each regional monsoon, the central box shows the index values in the control run, and the box to its east, north, west, and south displays the difference in which the control-run value is subtracted from the value of sensitivity experiment of EastTP_Alb05, NorthTP_Alb05, WestTP_Alb05, and SouthTP_Alb05, respectively. That is, the value of the eastern, northern, western, and southern box respectively measures the impact of eastern, northern, western, and southern TP on the specific regional monsoon. The values in parentheses represent the percentage (\%) change of the individual monsoon indices relative to the climatological means of the model control experiment. 
southern TP on the EASM (see values of percentage change in the brackets). Surprisingly, increased heating over all TP domains weakens the SEASM (see Fig. 3d).

Both the southern and northern TP exert their strongest impacts on weakening the SEASM (percentage change of $17.1 \%$ by the northern TP and $10.7 \%$ by the southern TP; Fig. 3d) and then strengthening the SASM $(8.8 \%$ by the northern TP and $7.9 \%$ by the southern TP; Fig. 3b), with the weakest effects of the southern TP on the EASM (0.4\%; Fig. 3c) and the weakest effects of the northern TP on the large-scale Asian monsoon (as represented by the W-Y index) (0.5\%; Fig. 3a). In this regard, the western TP is similar to the northern TP, exerting its strongest impacts on the SEASM and then the SASM, with the weakest impact on the large-scale monsoon. Northern TP heating also plays an important role in enhancing the EASM $(7.8 \%)$. Furthermore, the eastern TP most strongly intensifies the EASM (24.3\%; Fig. 3c) and then weakens the SEASM (Fig. 3d), while the western TP most strongly weakens the SEASM (15.7\%; Fig. 3d) and then intensifies the SASM (12.7\%; Fig. 3b). Both the eastern and western TP exert relatively weaker impacts on the large-scale Asian monsoon than on other regional monsoon components.

Interesting features can also emerge from analyzing the result with respect to the changes in the various monsoons. Intensification of the large-scale monsoon (Fig. 3a), the SASM (Fig. 3b), and the EASM (Fig. 3c) is most strongly affected by the heating over southern TP $(3.8 \%)$, western TP $(12.7 \%)$, and eastern TP $(24.3 \%)$, respectively. Indeed, all TP domains affect the SASM strongly, and thus the feature presented here is not necessarily inconsistent with previous results (Wu et al. 2012) in which the importance of southern TP for the SASM is emphasized. The large-scale monsoon (measured by the W-Y index) is least sensitive to the effects of northern and western TP domains, and the EASM responds more weakly to the southern TP relative to other domains. It is important to reiterate that the SEASM weakens associated with the warming over all TP domains. Studies of the impact of the western TP on the EASM are limited, and the recent analysis by Li et al. (2021) shows that sensible, radiative, and latent heating components of western TP lead to different types of atmospheric wave trains, which interact with the plateau and affect the intensity of the EASM.

We also point out that the demonstrated impact of TP on the East Asian monsoon measured by upper-tropospheric circulation (Lau et al. 2000) is consistent with the impact of the plateau on the monsoon assessed by a dynamical index based on the lower-tropospheric circulation (Wang 2002). In particular, the Lau et al. and Wang indices increase by $21.3 \%$ and $20.0 \%$, respectively, as a response to the entire-TP heating, and both indices show that the East Asian monsoon is most strongly affected by the eastern TP heating and most weakly affected by the southern TP heating. The changes in the South Asian monsoon measured by alternative indices will be discussed in section $3 \mathrm{~b}$ after the change in monsoon rainfall is depicted.

\section{b. Process-based explanations}

\section{1) IMPACT OF ENTIRE TP HEATING}

Figures $4 \mathrm{a}-\mathrm{c}$ show the climatological patterns of JJA 200-hPa winds, 850-hPa winds, precipitation, and vertically integrated water vapor flux (from 1000 to $200 \mathrm{hPa}$ ) from the CESM control experiment (CTRL). Noteworthy features include the upper-tropospheric South Asian high (SAH), with westerly (easterly) jet stream on its north (south), and the lower-tropospheric cyclonic pattern, with westerly (southerly) flow over South Asia (East Asia). The lower-tropospheric southerlies and northerlies to the east and west of TP are respectively linked to the WPSH and the anticyclonic pattern centered near the Mediterranean Sea (Fig. 4b). Accompanying heavy rainfall occurs over southern Asia-western Pacific regions including the southern edge of the TP, associated with large water vapor transport from the Arabian Sea, the Bay of Bengal, the SCS, and the far western Pacific (Fig. 4c). These features are overall similar with those in observations shown in many previous studies (e.g., Yang et al. 2008; Jiang et al. 2013b).

Figures 4d-f, which illustrate the differences in the above fields between the sensitivity experiment with enhanced heating over the entire TP and the control run CTRL, further explain the features of the TP's impact on monsoon shown in Fig. 2. The plateau heating unsurprisingly enhances the SAH overall (Fig. 4d), which is related with strengthened WPSH and enhanced lower-tropospheric southerly monsoon flow over East Asia (e.g., eastern China), and thus suppression of the atmospheric convection over the SCS and the Philippine Sea as discussed later. Although this enhancement apparently extends to the west, it is also accompanied by an anomalous anticyclonic pattern over East Asia and the western Pacific, leading to a northward shift of the westerly jet stream. At the lower troposphere (Fig. 4e), TP heating causes significant changes over the Asian-Pacific regions, which include an anomalous cyclonic pattern around the plateau (especially significant to its south and east) and intensification of the WPSH, consistently enhancing the regional monsoons (especially the SASM and the EASM) except the SEASM (see Fig. 2). An anomalous cyclonic (anticyclonic) pattern appears over the Middle East and North Africa (the Mediterranean Sea region), and a vertical-westward tilted anomalous cyclonic pattern occurs over central Eurasia (near $55^{\circ} \mathrm{N}, 50^{\circ} \mathrm{E}$ ).

As shown in Fig. 4f, TP heating enhances the rainfall over the southern and eastern portions of the plateau (and their vicinities), northern China, the waters off southeastern China, and the southern Bay of Bengal. However, it decreases the rainfall over tropical Asia at $15^{\circ}-25^{\circ} \mathrm{N}$, southwest of the plateau, and the Southeast Asian-western Pacific regions. The roughly out-of-phase change in rainfall between the TP and the Indian subcontinent is consistent with the dipole-type distribution of rainfall variation discussed in Jiang and Ting $(2017,2019)$. These changes in rainfall are closely related to atmospheric water vapor fluxes (see the vectors in Fig. 4f), whose convergence and divergence (figure not shown) are consistent with the increase and decrease in rainfall, respectively. The TP heating enables more water vapor to flow into the TP region, instead of confining it to the south of the plateau. Moreover, the rainfall enhancement over the southern slope of TP and northern East Asia and the rainfall reduction over Southeast Asia and far western Pacific are again consistent with the 
(a) UV200 (CTRL)

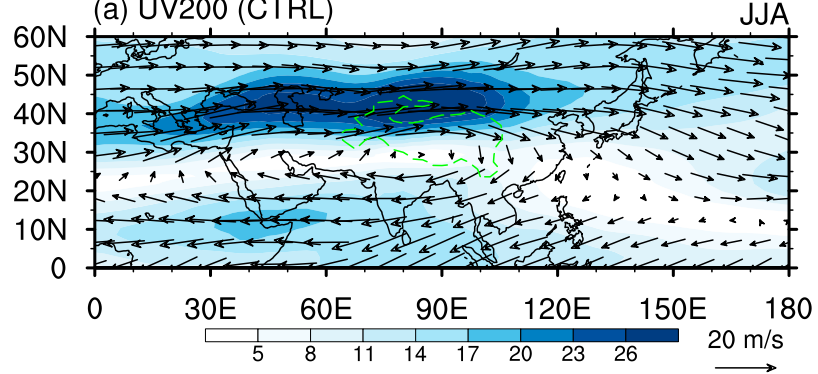

(b) UV850 (CTRL)

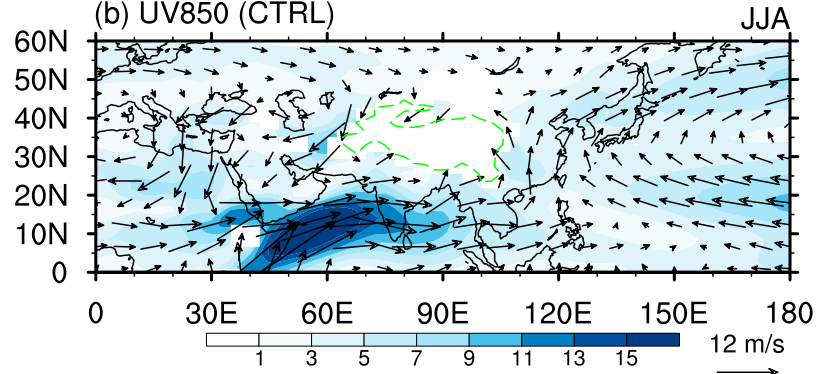

(c) Precip \& WVF (CTRL)

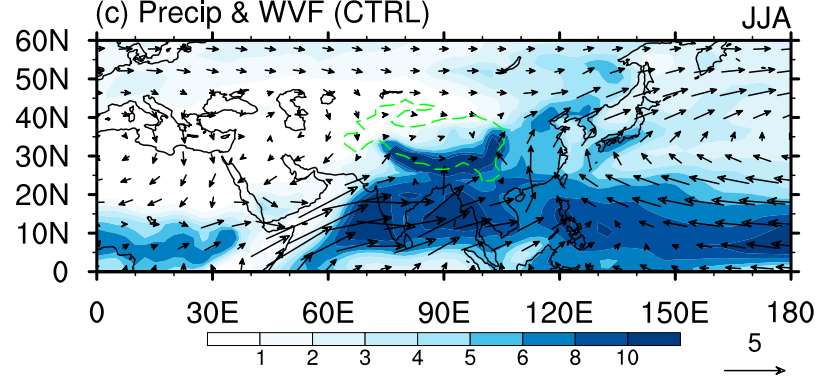

(d) Diffs. in UV200 (TP Alb05 - CTRL)

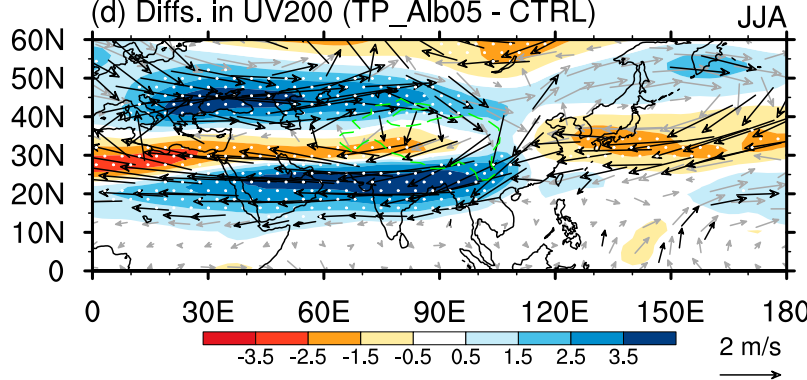

(e) Diffs. in UV850 (TP_Alb05 - CTRL)

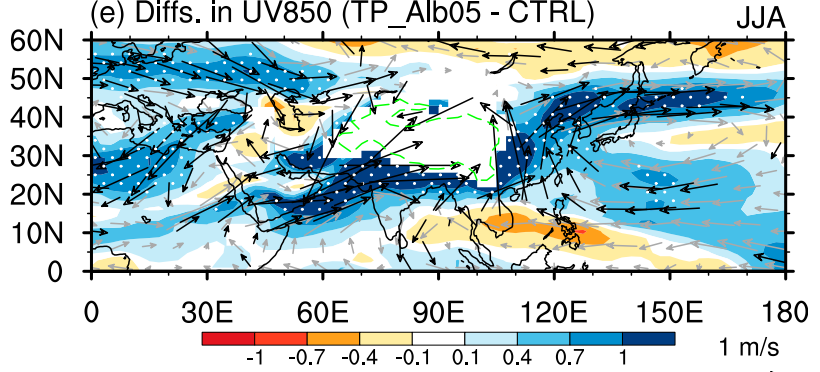

(f) Diffs in Precip \& WVF (TP Alb05 - CTRL)

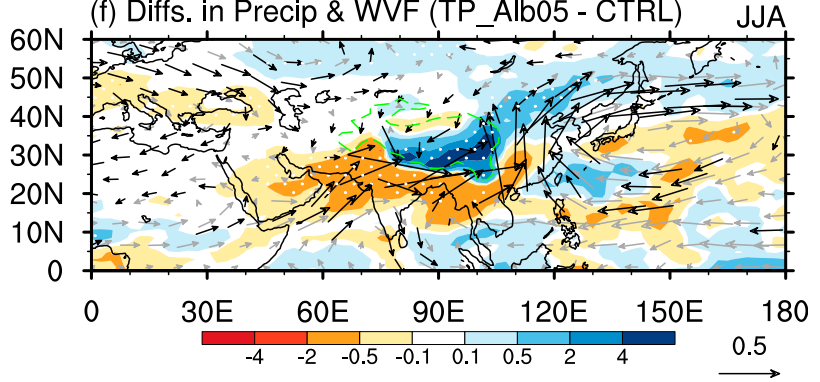

FIG. 4. Climatological patterns of the CTRL experiment for JJA (a) 200-hPa winds (vectors; $\mathrm{m} \mathrm{s}^{-1}$ ), (b) 850-hPa winds (vectors; $\mathrm{m} \mathrm{s}^{-1}$ ), and (c) precipitation (shading; $\mathrm{mm} \mathrm{day}^{-1}$ ) and vertically integrated water vapor flux [vectors; $100 \mathrm{~kg}(\mathrm{~m} \mathrm{~s})^{-1}$ ]. Also shown are the corresponding differences between TP_Alb05 and CTRL experiments in JJA (d) 200-hPa winds, (e) 850-hPa winds, and (f) precipitation and vertically integrated water vapor flux. In (a), (b), (d), and (e), the color shades measure the speed of the winds. White stippling and black vectors indicate values above the $95 \%$ confidence level. The topography of the TP above $1500 \mathrm{~m}$ is marked with the dashed green contour.

increase in SASM and EASM indices and the decrease in the SEASM monsoon index. Apparently, the northward shift of the East Asian jet stream and the strengthening of WPSH are accompanied by the northward extension of heavy rainfall over East Asia, an indication of strong EASM. On the other hand, the WPSH intensification with enhanced negative vorticity weakens the SEASM and reduces rainfall over Southeast Asia. These results are partially similar to those of B. He et al. (2019), who conducted experiments using the coupled Flexible Global Ocean-Atmosphere-Land System Model (Bao et al. 2013) to understand the climate impact of TP thermal effect, and Wang et al. (2016), who applied the regional model WRF and showed that enhanced monsoon rainfall associated with TP heating was mainly concentrated over the southern slope of the TP.

We further similarly examine the changes in more monsoon indices: the index of Webster et al. (1998), defined as the vertical shear of 850 - and $200-\mathrm{hPa}$ zonal winds over $5^{\circ}-20^{\circ} \mathrm{N}$, $60^{\circ}-110^{\circ} \mathrm{E}$, and the index by Wang et al. (2001), defined by the vorticity as the horizontal shear of $850-\mathrm{hPa}$ zonal winds between southern India $\left(5^{\circ}-15^{\circ} \mathrm{N}, 60^{\circ}-80^{\circ} \mathrm{E}\right)$ and northern India $\left(20^{\circ}-30^{\circ} \mathrm{N}, 70^{\circ}-90^{\circ} \mathrm{E}\right.$ ) (the former box minus the latter box). It is found that the response of Webster et al. (1998) index to TP heating is similar to that of the Webster and Yang (1992) index, which is not surprising given the similar definitions of the two indices, and both indices respond most strongly to southern TP heating (see discussion later). However, the change in the Wang et al. (2001) index reveals more dynamical features. Despite its negative sign, the change in the index reflects a stronger intensification of 850$\mathrm{hPa}$ monsoon westerlies over northern India than southern India as a response to TP heating. As a result, water vapor divergence and decreased rainfall occur over the relatively lower latitudes and increased rainfall appears over the southern uphill of the TP. The stronger intensification of monsoon flow over the north, relative to the south, is also consistent with the importance of the thermal effect of the TP (especially the southern TP; see discussion later) for the 
(a) H500 (CTRL)

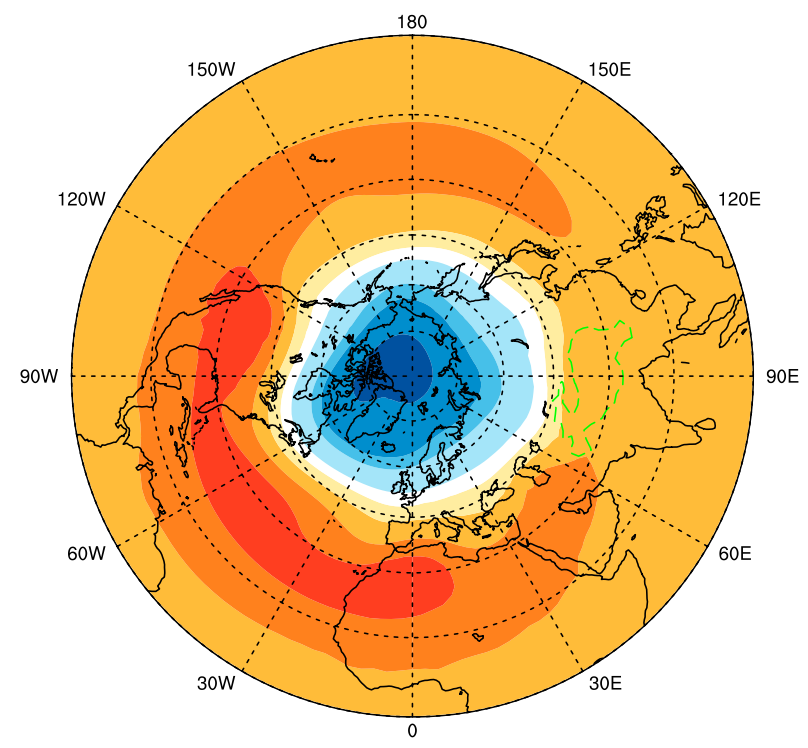

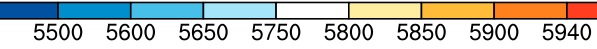

(b) Diff. in H500 (TP_Alb05 - CTRL)

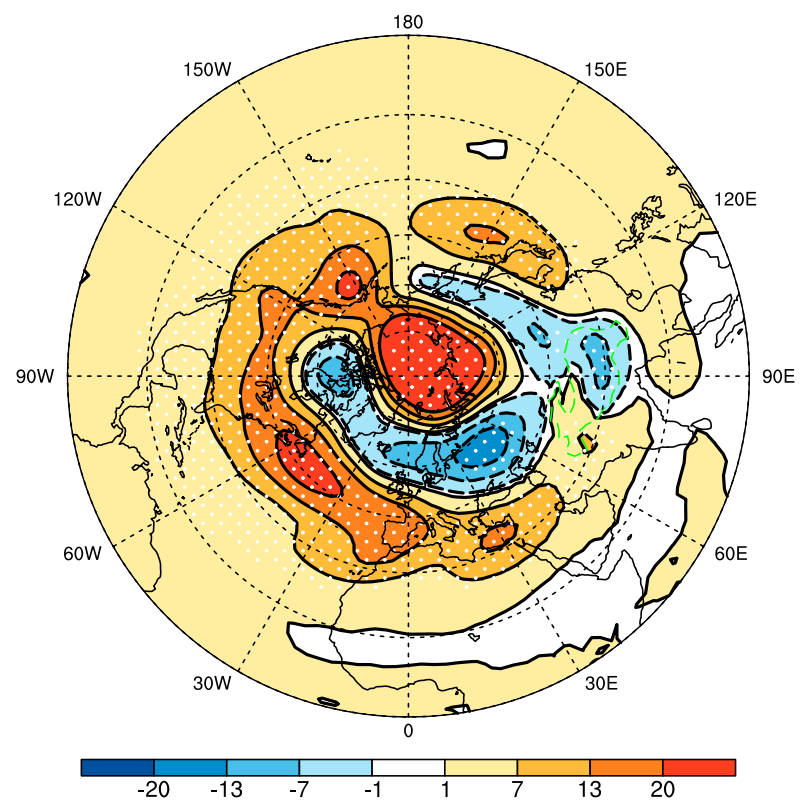

FIG. 5. (a) The climatological pattern of JJA 500-hPa geopotential height (H500) (shading, $\mathrm{m}$ ) in the CTRL experiment, and (b) the difference (shading and contours) in $\mathrm{H} 500$ between the TP Alb05 and CTRL experiments. In (b), the white stippling indicates values above the $95 \%$ confidence level.

northern branch of the South Asian monsoon circulation demonstrated by Wu et al. (2015).

Tibetan Plateau thermal effects lead to significant features of the change in 500-hPa geopotential height (H500; Fig. 5). In the latitude band of $15^{\circ}-40^{\circ} \mathrm{N}, \mathrm{H} 500$ increases significantly except at the eastern TP and to its north where H500 decreases, enhancing the zonal gradient of the middle-lower troposphere across the TP (cf. Figs. 5b and 5a). It lowers in the Eastern Hemisphere and raises in the Western Hemisphere, tending to form a wavenumber- 1 structure, in $40^{\circ}-60^{\circ} \mathrm{N}$ and changes oppositely in the higher latitudes. Similar features also appear from the Northern Hemisphere patterns of differential tropospheric temperature (figure not shown), although it is apparently high over the TP, which is unsurprising given the nature of vertical integration of temperature from 700 or $500 \mathrm{hPa}$ (warmer than the outside atmosphere) to $200 \mathrm{hPa}$.

The following features can hence be summarized by analyzing Figs. 2, 4, and 5. The increase in large-scale monsoon index (Webster and Yang 1992) is clearly associated with zonally extensive strengthening of U200 and U850 over tropical to subtropical Asia, weighted by the change in U200, and the intensification of the South Asian monsoon (Goswami et al. 1999) is related to the anomalous $850-\mathrm{hPa}$ southerlies and $200-\mathrm{hPa}$ northerlies averaged over $10^{\circ}-30^{\circ} \mathrm{N}$, $70^{\circ}-110^{\circ} \mathrm{E}$ (Figs. $4 \mathrm{~d}-\mathrm{e}$ ). The strengthened (weakened) U200 over $40^{\circ}-50^{\circ} \mathrm{N}\left(25^{\circ}-35^{\circ} \mathrm{N}\right)$ in the longitudes of $110^{\circ}-150^{\circ} \mathrm{E}$ intensifies the East Asian monsoon as defined by Lau et al. (2000) (Fig. 4d), and in particular the apparent intensification of this regional monsoon is related to the large zonal difference in H500 anomaly over East Asia (Fig. 5b). Moreover, the anomalous easterlies related to the strong WPSH reduce the lower-tropospheric vorticity and account for the slight weakening of the Southeast Asian monsoon (Wang and Fan 1999) (Fig. 4e).

\section{2) IMPACTS OF VARIOUS TP DOMAINS}

We now analyze the features of the physical processes related to the impacts of different TP domains on regional Asian monsoons. Figure 6 shows that the heating of various TP domains strengthens the SAH overall, as does the heating of entire TP, which causes a center of SAH change around $35^{\circ} \mathrm{N}, 70^{\circ} \mathrm{E}$ (Fig. 4d). However, a careful examination indicates that the heating of the southern and eastern TP causes the center to move farther eastward (to $85^{\circ}$ and $100^{\circ} \mathrm{E}$, respectively) (Figs. 6a,c) and the southern TP heating even shifts the center southward to about $30^{\circ} \mathrm{N}$. It is only the eastern TP heating that can generate from a single domain a significant anomalous anticyclonic pattern over the extratropical western Pacific that is similar to that of the entire TP heating (cf. Figs. 6c and 4d), despite the fact that a weak anticyclonic pattern is also caused by southern TP heating. All experiments generate anomalous upper-tropospheric easterlies over the subtropics west of $120^{\circ} \mathrm{E}$ and westerlies over the extratropics $\left(35^{\circ}-50^{\circ} \mathrm{N}\right)$ west of the $\mathrm{TP}$, but the anomalous westerlies are not significant in NorthTP_Alb05 (Fig. 6b).

As depicted by Fig. 7, the changes in the lower troposphere tend to reveal more regional features; however, none of the single domain experiments of the southern, northern, eastern, or western TP can explain all the features generated by the entire-TP experiment (Fig. 4e). Specifically, the significant features in the southern TP experiment account for the intensifications of the westerly monsoon flow immediately next to the southern edge of the TP and the anticyclonic pattern 
(a) Diffs. in UV200 (SouthTP Alb05 - CTRL)

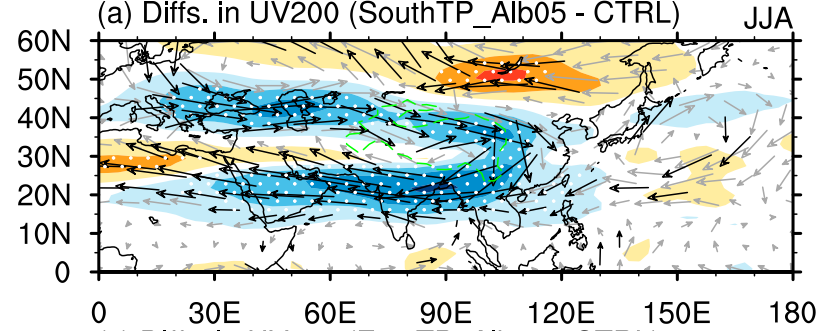
(c) Diffs. in UV200 (EastTP_Alb05 - CTRL)

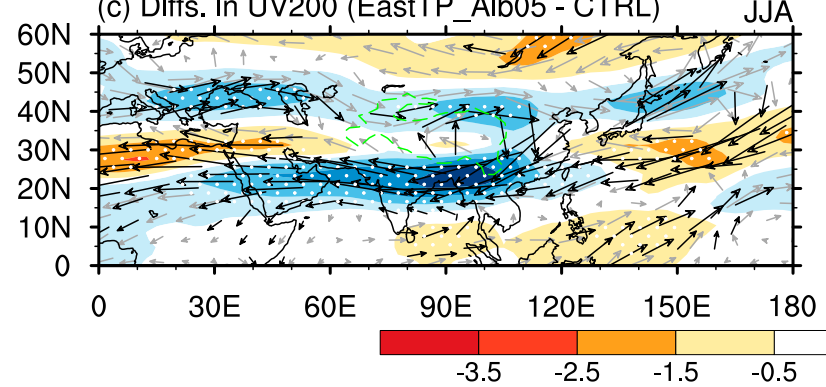

(b) Diffs. in UV200 (NorthTP Alb05 - CTRL)

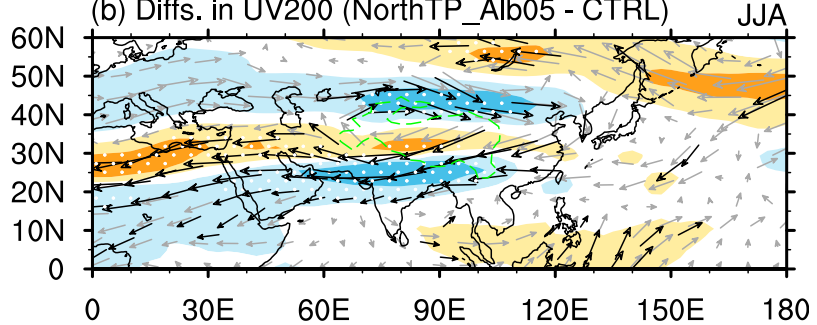

(d) Diffs. in UV200 (WestTP Alb05 - CTRL)

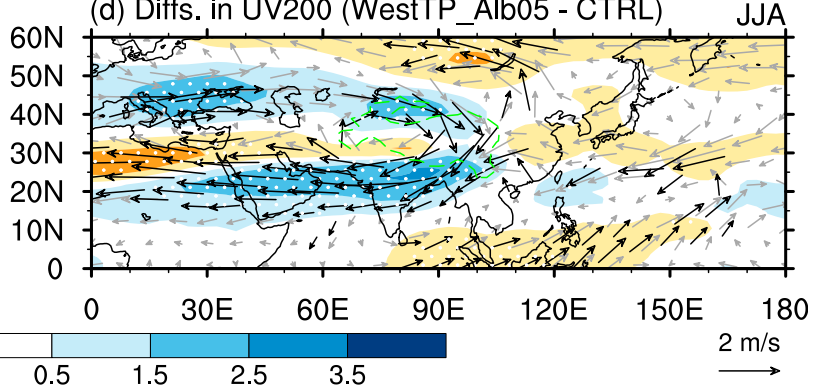

FIG. 6. Differences in JJA 200-hPa winds (vectors; $\mathrm{m} \mathrm{s}^{-1}$ ) (a) between SouthTP_Alb05 and CTRL, (b) between NorthTP_Alb05 and CTRL, (c) between EastTP_Alb05 and CTRL, and (d) between WestTP_Alb05 and CTRL. Color shades measure the speed of the winds. White stippling and black vectors indicate values above the $95 \%$ confidence level. The topography of the TP above $1500 \mathrm{~m}$ is marked with the dashed green contour.

over the Mediterranean Sea (cf. Figs. 7a and 4e), with few features over East Africa, and those in northern TP experiment (Fig. 7b) account for the intensifications of cyclonic patterns over North Africa and around the TP, with strong signals on its northwest and east but weak signals on the south. While southern TP heating increases the rainfall mainly over the southern and eastern plateau as in the entire-TP experiment, northern TP heating enhances the rainfall over the northern plateau domain and to its northeast. The northern TP heating also enhances the Pacific trade wind south of $15^{\circ} \mathrm{N}$ (Fig. $7 \mathrm{~b}$ ), which is favorable for enhancing the southerlies over eastern China and increasing the rainfall over southern Southeast Asia. As seen from Figs. $7 \mathrm{c}$ and $7 \mathrm{~d}$, the eastern TP heating strengthens the monsoon flow to the south and east of the plateau and even most significantly the WPSH, and the western TP heating is accompanied by significant features over west of $120^{\circ} \mathrm{E}$ especially over West Asia. The eastern TP heating leads to a rainfall change pattern that is similar to that in the southern TP heating case, and the western TP heating enhances the rainfall over southwestern plateau and to the (a) Diffs. in Precip \& UV850 (SouthTP_Alb05 - CTRL) JJA
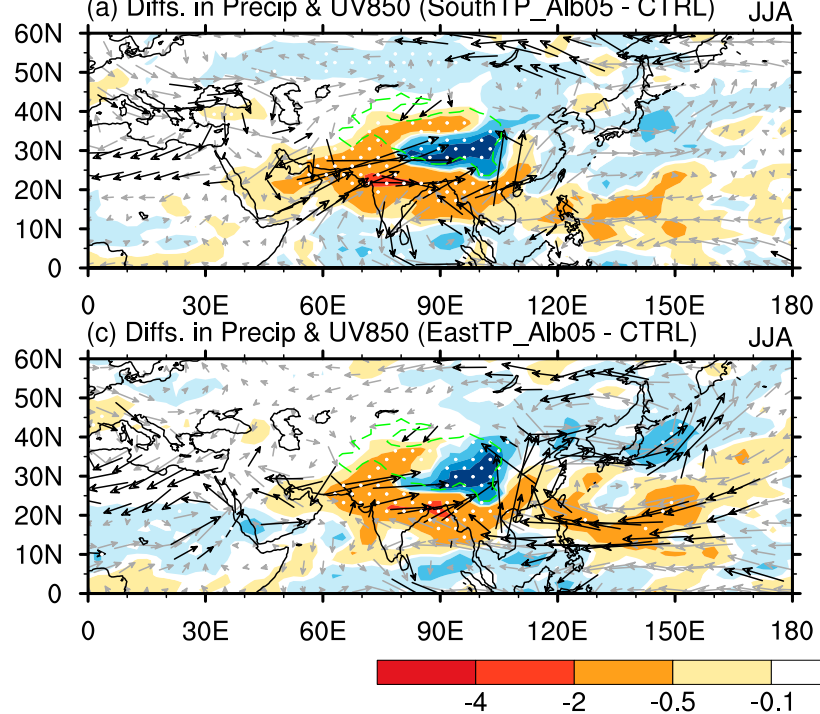

(b) Diffs. in Precip \& UV850 (NorthTP_Alb05 - CTRL)

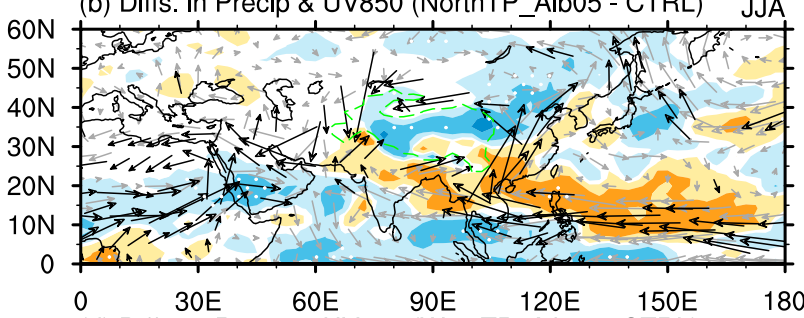

(d) Diffs. in Precip \& UV850 (WestTP_Alb05 - CTRL) JJA

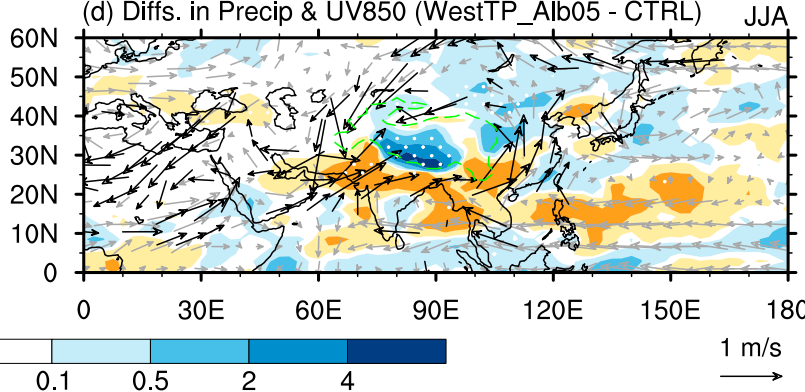

FIG. 7. Similar to Fig. 6, but for differences in JJA 850 -hPa winds (vectors; $\mathrm{m} \mathrm{s}^{-1}$ ) and precipitation (shading; $\mathrm{mm}^{-1 a y}{ }^{-1}$ ) between (a) SouthTP_Alb05 and CTRL, (b) NorthTP_Alb05 and CTRL, (c) EastTP_Alb05 and CTRL, and (d) WestTP_Alb05 and CTRL. 
(a) Diff. in H500 (SouthTP_Alb05 - CTRL)

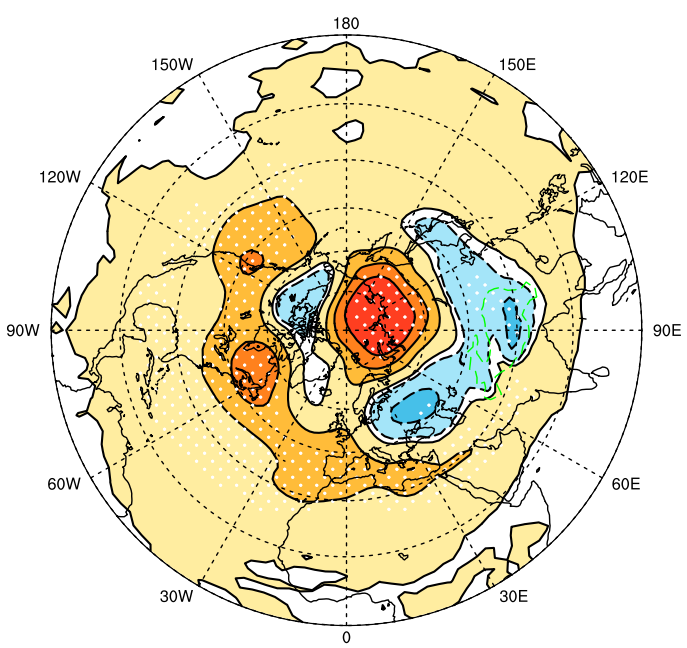

(c) Diff. in H500 (EastTP_Alb05 - CTRL) (b) Diff. in H500 (NorthTP_Alb05 - CTRL)

JJA

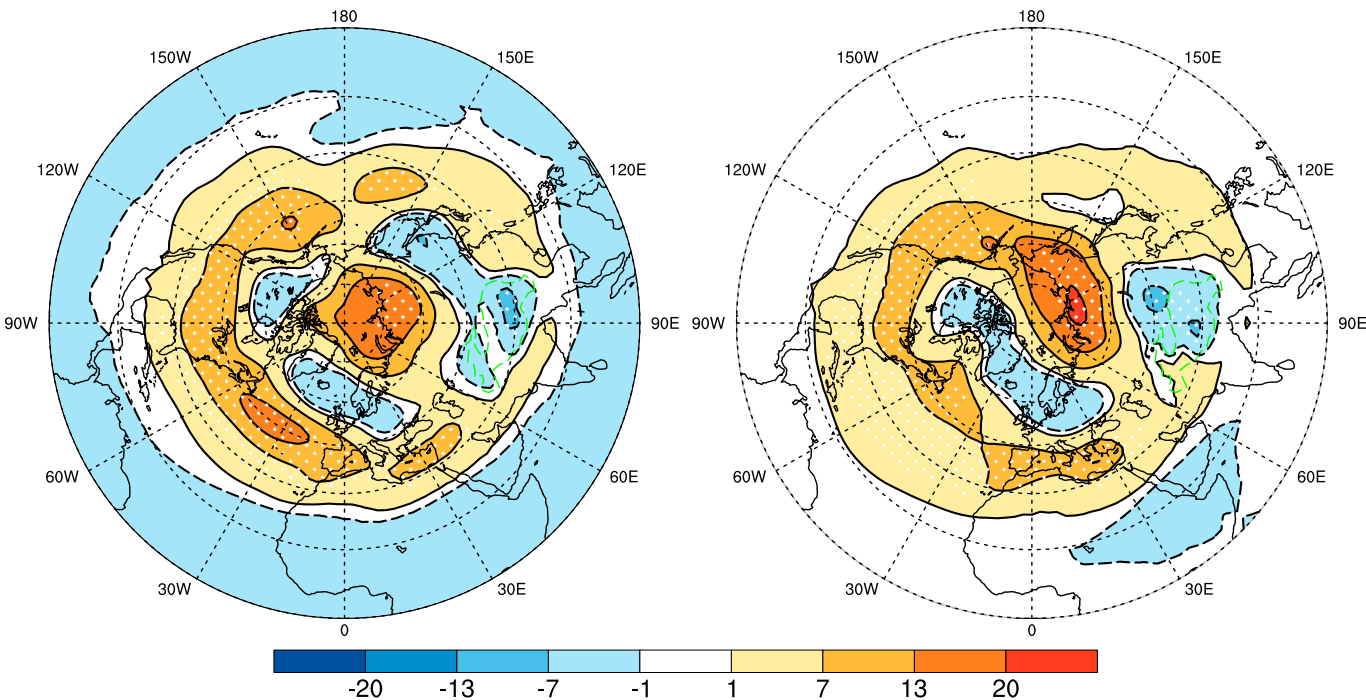

FIG. 8. Differences in JJA 500-hPa geopotential height (shading and contours; m) between (a) SouthTP_Alb05 and CTRL, (b) NorthTP_Alb05 and CTRL, (c) EastTP_Alb05 and CTRL, and (d) WestTP_Alb05 and CTRL. White stippling indicates values above the $95 \%$ confidence level. The topography of the TP above $1500 \mathrm{~m}$ is marked with the dashed green contour.

northeast of the TP. It is important to know that neither the southern TP heating nor the western TP heating causes significant change over the western Pacific and much of Southeast Asia (Figs. 7a and 5d), while the heating over both the northern TP and eastern TP leads to strengthened and westward extended WPSH that affects the rainfall over the SCS and tropical western Pacific (Figs. 7b,c). All these features manifest a weakening of the SEASM (see Fig. 3), which is dynamically linked to the change in the WPSH (Wang and Fan 1999; Wang et al. 2008b), and consistently the decrease in monsoon rainfall over the northern SCS, the Philippines, and the Philippine Sea.

Analysis of the changes in H500 (Fig. 8) indicates that the southern and eastern TP heating generates similar anomalous patterns over the plateau and eastward from the North Pacific,
North America, the North Atlantic, and the Mediterranean Sea to West Asia. However, the northern TP heating, which is uniquely accompanied by a center of decreased H500 over the northeast of the TP instead over the plateau, tends to most significantly generate a nearly circumglobal wave train pattern (Fig. 8b). This feature demonstrates the importance of northern TP heating for affecting the rotational portion of atmospheric motion in comparison with the heating over other TP domains. It is also important to observe that in all experiments shown in Fig. 8, as well as in Fig. 5b for the entire-TP heating experiment, the heating over the TP and its various domains causes increased geopotential height over the Middle East and the Mediterranean Sea. The sinking motion associated with the anomalous high and its relation with the rising motion 

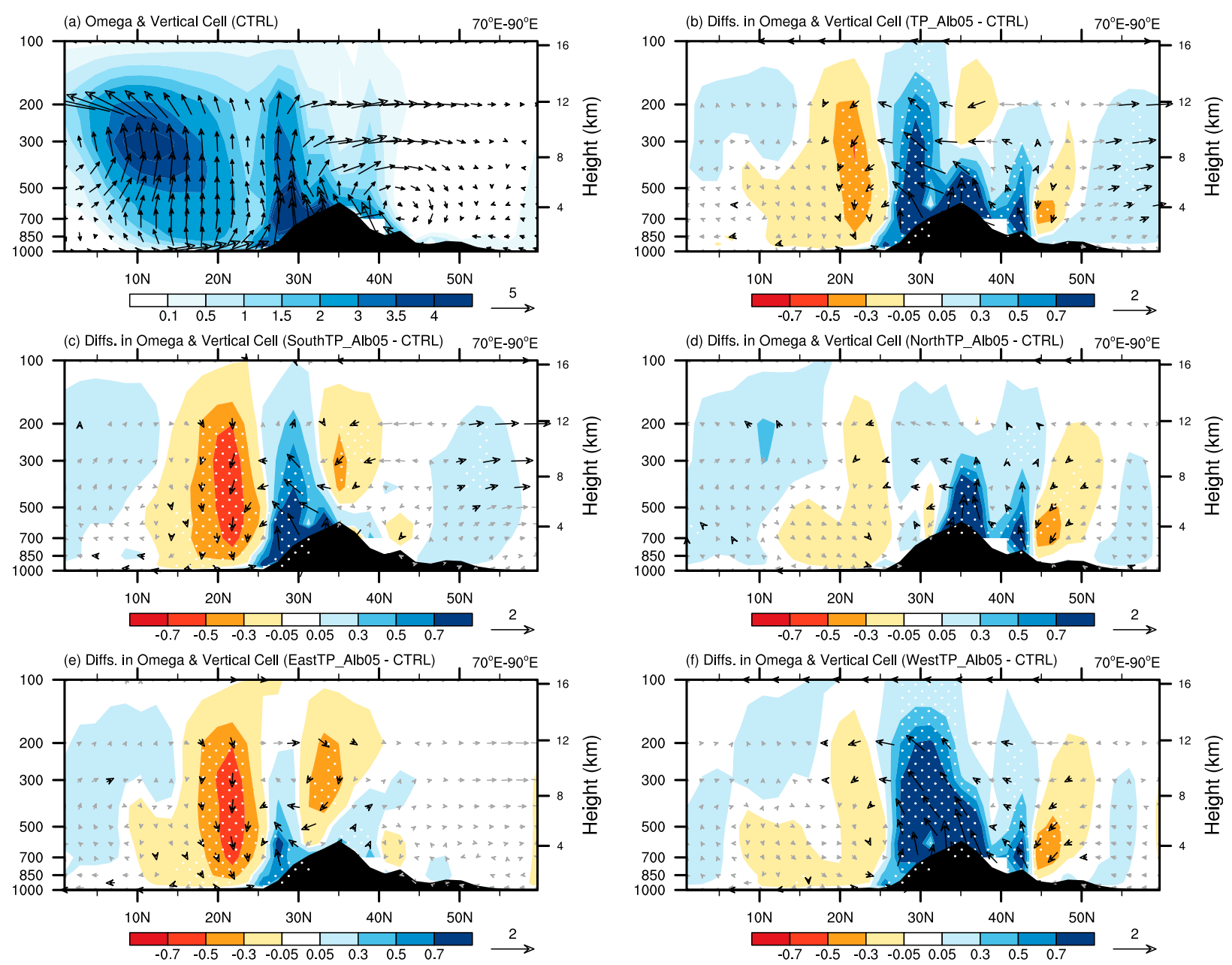

FIG. 9. Latitude-height vertical circulations (vectors, with vertical velocity multiplied by 50 ) and vertical motions (shading; Pa $\mathrm{s}^{-1}$ ) averaged over $70^{\circ}-90^{\circ} \mathrm{E}$ for (a) the CTRL experiment, and the differences between (b) TP_Alb05 and CTRL, (c) SouthTP_Alb05 and CTRL, (d) NorthTP_Alb05 and CTRL, (e) EastTP_Alb05 and CTRL, and (f) WestTP_Alb05 and CTRL. White stippling and black vectors indicate values above the $95 \%$ confidence level. The topography of the TP is marked with black shading.

over the plateau and adjacent regions can be explained by the monsoon-desert linkage (Song et al. 1992; Webster et al. 1998), emphasizing the zonally direct circulation or the "transverse monsoon," or by the monsoon-desert mechanism (Rodwell and Hoskins 1996; Hoskins and Wang 2006) in which the Rossby wave response to monsoon heating is stressed. An analysis of the tropospheric temperature also reveals similar features outside the TP.

Figure 9a shows that, over the longitudes of $70^{\circ}-90^{\circ} \mathrm{E}$, extensive rising motions appear over the Indian monsoon region and the TP from $5^{\circ}$ to $40^{\circ} \mathrm{N}$. Relatively weaker sinking motions occur near the equator and to the north of $40^{\circ} \mathrm{N}$. The effect of entire TP heating strengthens the rising motions over $25^{\circ}-45^{\circ} \mathrm{N}$ and weakens the rising motions to the south, especially over $20^{\circ}-25^{\circ} \mathrm{N}$ (Fig. 9b). The resulting change extends deeply into the upper troposphere over the southern portion of the TP and to its south, but it is shallower to the north.

It is interesting to note that the southern TP heating explains and even amplifies the anomalous vertical cell over the southern TP edge and to its south, consistent with the change in South Asian rainfall (Fig. 7), but accounts for little change over the northern TP edge and to its north (cf. Figs. 9c and 9b). Oppositely, the northern TP heating explains the anomalous vertical cell over the northern TP edge and to its north, but accounts for little change over the southern TP edge and to its south (Fig. 9d). It can also be seen that the eastern TP heating (Fig. 9e) leads to similar features as the southern TP heating except causing weaker signals especially the rising motion over the southern TP. Moreover, the western TP heating leads to similar but stronger features as the northern TP heating, especially the strong rising motion over the southern TP (Fig. 9f). We point out that the above features shown in Fig. 9 (over $70^{\circ}-90^{\circ} \mathrm{E}$ ) also similarly appear from the latitudinal-vertical section over $70^{\circ}-110^{\circ} \mathrm{E}$ (figure not shown) and the longitude band of specified TP forcing in the sensitivity experiments, demonstrating the robustness of the features discussed.

Analysis of the vertical cells over $100^{\circ}-120^{\circ} \mathrm{E}$ places more interest in the East and Southeast Asian monsoons (Fig. 10). 

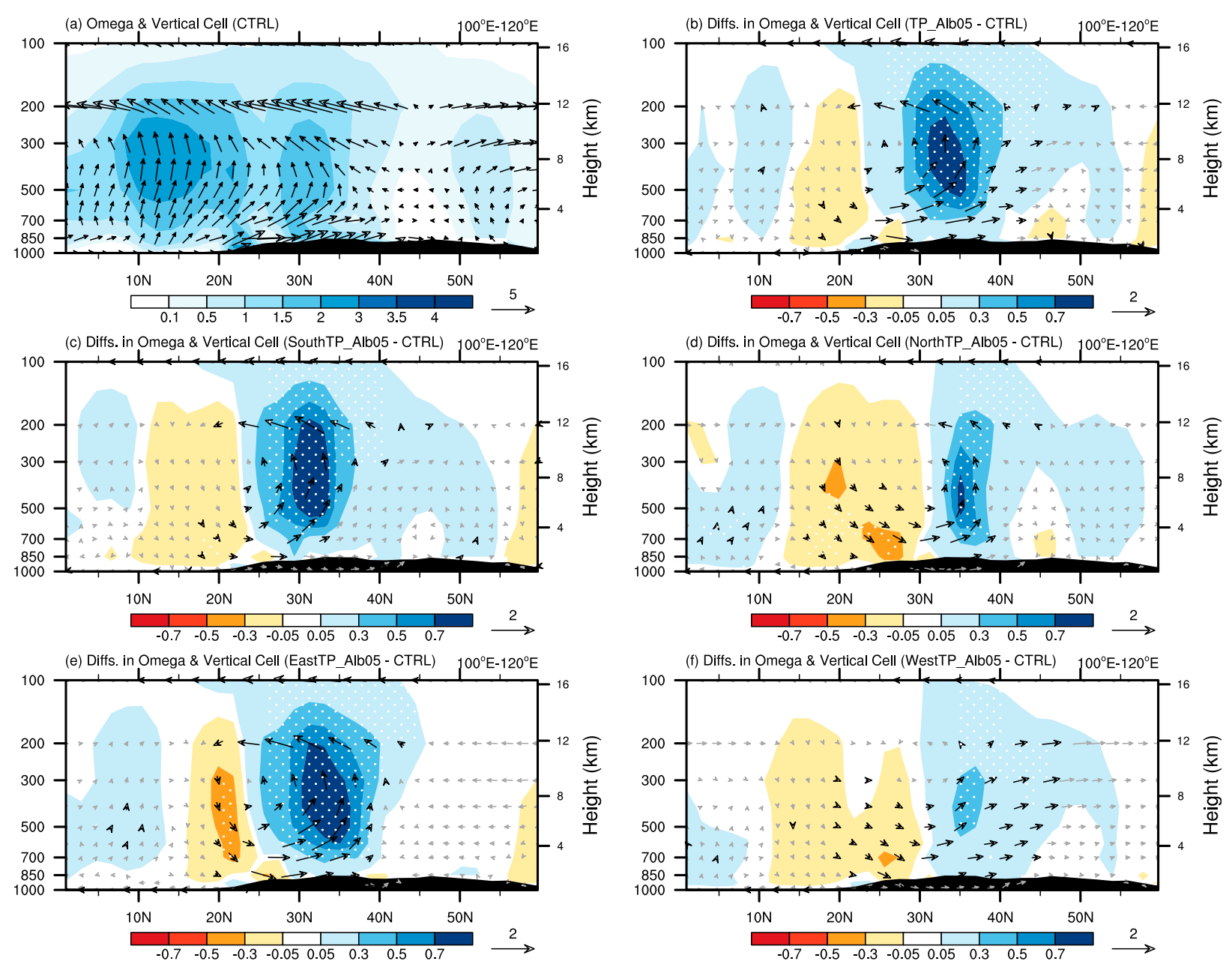

FIG. 10. As in Fig. 9, but for the longitudinal band of $100^{\circ}-120^{\circ} \mathrm{E}$.

Here, TP heating causes an anomalous vertical cell over the subtropics with apparent rising motions over $30^{\circ}-40^{\circ} \mathrm{N}$ (Fig. 10b), associated with intensification of the EASM (see Fig. 2). However, it exerts a weak impact on the tropics (e.g., Southeast Asia), as seen from the change in the regional monsoon (SEASM; see Fig. 2). The anomalous rising motions are accounted for by the heating over southern and eastern plateau (Figs. 10c,e), with little contribution from the western TP heating (Fig. 10f). On the other hand, the northern and eastern TP heating leads to most apparent sinking motions in the subtropics (around $20^{\circ} \mathrm{N}$ ), which are weakly influenced by the southern and western TP heating.

\section{Conclusions and discussion}

In this study, we have attempted to shed light on the characteristics of TP thermal impact on the Asian summer monsoon and associated physical processes, with a focus on the regional features of both the plateau heating and the monsoon. More specifically, we have applied the NCAR CESM to quantitatively depict how the heating over TP and its different domains (the southern, northern, eastern, and western portions of plateau) affects the tropical SASM and SEASM, the subtropical EASM, and the large-scale monsoon circulation.

The heating over TP and its various domains intensifies the SASM; however, it surprisingly slightly weakens the SEASM. The TP heating causes anomalous rising motion over the plateau and compensating sinking motion and thus a weaker monsoon over Southeast Asia. It is also surprising to find that although southern TP heating most effectively intensifies the large-scale monsoon circulation (measured by the $\mathrm{W}$-Y index), it exerts little effect on the EASM, which is instead affected most strongly by eastern TP heating. Overall, relative to their northern and western counterparts, the southern and eastern portions of the TP exert stronger impacts on monsoon climate as evidenced by both the strength and the spatial extension of monsoon response signals, attributed probably to the abundant water vapor and deep convection in these tropical or ocean-neighboring regions. The extratropical northern TP heating plays a small role in intensifying tropical monsoons (e.g., the W-Y index); however, it strengthens the subtropical EASM. More importantly, it leads to apparent changes in the 
atmospheric rotational motion as evidenced by the significant wave train that extends eastward from the TP to western Eurasia as a circumglobal pattern over the higher latitudes. This feature may be helpful for explaining how the "upstream" summer climate over the North Atlantic and southern Europe responds to TP heating as explored by Lu et al. (2018). Last, the western TP heating, which is accompanied by moderate wavetype anomalous signals to the west of the plateau, seems to exert the weakest impact on the large-scale monsoon circulation (as measured by the $\mathrm{W}-\mathrm{Y}$ index) relative to other monsoon components.

We point out that our conclusions are obtained based on an analysis of the model outputs of the last 40 years from $50-\mathrm{yr}$ model integrations, which were continued from a 250-yr spinup run. An additional analysis of the outputs from just 20 years yields features that are largely similar to those presented in the paper, demonstrating the robustness of the results discussed.

One of the issues that deserves further investigation is the impact of TP on the Southeast Asian monsoon as explored by examining the features associated with monsoon index SEASM (Wang and Fan 1999) and its associated rainfall pattern in this study. Although the SEASM was also considered an index for the East Asian monsoon (Wang and Fan 1999; Wang et al. 2008b) and the Southeast Asian monsoon was regarded as part of the East Asian monsoon in some studies (e.g., Tao and Chen 1987), Yoo et al. (2006; see their Fig. 6b) showed that the SEASM was solidly linked with the circulation and rainfall features over Southeast Asia and the Philippine Sea. Given the different, and even opposite signed, response of the SEASM to TP heating when compared with other monsoon components, further investigations aiming at more evidence of the thermal effect of the TP on this particular regional monsoon and the associated physical mechanisms are carried out. It is reasonable to state that the thermal conditions over the TP and East Asia interact with each other. As revealed by Jiang et al. (2016), the convection around the western "Maritime Continent" plays an important role in the interannual variation of the summertime atmospheric heat source over the TP. Preliminary analysis also indicates that TP heating suppresses the atmospheric convection over the SCS and the Philippine Sea associated with the strengthened WPSH and lower-tropospheric southerly monsoon flow over East Asia (e.g., eastern China) as shown in Fig. 4f.

Furthermore, the TP affects not only the seasonal-mean intensity of the Asian monsoon but also the temporal evolution of the monsoon. It is reasonably assumed that, like the entire plateau, the different portions of the TP also exert different impacts on the subseasonal evolution of the various regional Asian monsoon components, and the issue has not been investigated in the current study but is being addressed currently by applying an analysis with observations and model output of higher temporal resolutions.

Acknowledgments. The authors thank Profs. Bin Wang, Ziqian Wang, and Guoxiong Wu for several valuable discussions. The comments and suggestions from three anonymous reviewers were helpful for improving the overall quality of this paper. This study was supported by the National Natural
Science Foundation of China (Grants 91637208, 42088101, 41690123, and 41690120), Guangdong Major Project of Basic and Applied Basic Research (Grant 2020B0301030004), the Natural Science Foundation of Guangdong Province (Grant 2018A0303130268), the Pearl River S\&T Nova Program of Guangzhou (Grant 201906010054), Guangdong Province Key Laboratory for Climate Change and Natural Disaster Studies (Grant 2020B1212060025), and the Jiangsu Collaborative Innovation Center for Climate Change. Author Lu thanks the China Scholarship Council program for providing support for her stay at Harvard University.

\section{REFERENCES}

Abe, M., A. Kitoh, and T. Yasunari, 2003: An evolution of the Asian summer monsoon associated with mountain uplift-Simulation with the MRI atmosphere-ocean coupled GCM. J. Meteor. Soc. Japan, 81, 909-933, https://doi.org/10.2151/jmsj.81.909.

— M. Hori, T. Yasunari, and A. Kitoh, 2013: Effects of the Tibetan Plateau on the onset of the summer monsoon in South Asia: The role of the air-sea interaction. J. Geophys. Res., 118, 1760-1776, https://doi.org/10.1002/jgrd.50210.

Bao, Q., and Coauthors, 2013: The Flexible Global Ocean-AtmosphereLand system model, spectral version 2: FGOALS-s2. $A d v$. Atmos. Sci., 30, 561-576, https://doi.org/10.1007/s00376012-2113-9.

Boos, W., and Z. Kuang, 2010: Dominant control of the South Asian monsoon by orographic insulation versus plateau heating. Nature, 463, 218-222, https://doi.org/10.1038/nature08707.

$\longrightarrow$, and - 2013: Sensitivity of the South Asian monsoon to elevated and non-elevated heating. Sci. Rep., 3, 1192, https:// doi.org/10.1038/srep01192.

Cai, M., and J. Lu, 2009: A new framework for isolating individual feedback processes in coupled general circulation climate models. Part II: Method demonstrations and comparisons. Climate Dyn., 32, 887-900, https://doi.org/10.1007/s00382-0080424-4.

Dee, D. P., and Coauthors, 2011: The ERA-Interim reanalysis: Configuration and performance of the data assimilation system. Quart. J. Roy. Meteor. Soc., 137, 553-597, https://doi.org/ 10.1002/qj.828.

Duan, A., F. Li, M. Wang, and G. Wu, 2011: Persistent weakening trend in the spring sensible heat source over the Tibetan Plateau and its impact on the Asian summer monsoon. J. Climate, 24, 5671-5682, https://doi.org/10.1175/JCLI-D-1100052.1.

—, M. Wang, Y. Lei, and Y. Cui, 2013: Trends in summer rainfall over China associated with the Tibetan Plateau sensible heat source during 1980-2008. J. Climate, 26, 261-275, https:// doi.org/10.1175/JCLI-D-11-00669.1.

Flohn, H., 1957: Large-scale aspects of the "summer monsoon" in South and East Asia. J. Meteor. Soc. Japan, 75, 180-186, https://doi.org/10.2151/jmsj1923.35A.0_180.

Goswami, B. N., V. Krishnamurthy, and H. Annamalai, 1999: A broad scale circulation index for the interannual variability of the Indian summer monsoon. Quart. J. Roy. Meteor. Soc., 125, 611-633, https://doi.org/10.1002/qj.49712555412.

Hahn, D. G., and S. Manabe, 1975: The role of mountains in the South Asian monsoon circulation. J. Atmos. Sci., 32, 15151541, https://doi.org/10.1175/1520-0469(1975)032<1515:TROMIT> 2.0.CO;2.

He, B., Y. Liu, G. Wu, Z. Wang, and Q. Bao, 2019: The role of airsea interactions in regulating the thermal effect of the Tibetan- 
Iranian Plateau on the Asian summer monsoon. Climate Dyn., 52, 4227-4245, https://doi.org/10.1007/s00382-018-4377-y.

He, C., Z. Wang, T. Zhou, and T. Li, 2019: Enhanced latent heating over the Tibetan Plateau as a key to the enhanced East Asian summer monsoon circulation under a warming climate. J. Climate, 32, 3373-3388, https://doi.org/10.1175/JCLI-D-180427.1.

He, H., J. W. McGinnis, Z. Song, and M. Yanai, 1987: Onset of the Asian summer monsoon in 1979 and the effect of the Tibetan Plateau. Mon. Wea. Rev., 115, 1966-1995, https://doi.org/ 10.1175/1520-0493(1987)115<1966:OOTASM > 2.0.CO;2.

Hoskins, B. J., and B. Wang, 2006: Large-scale atmospheric dynamics. The Asian Monsoon, B. Wang, Ed., Springer, 357-416.

Hsu, H., and X. Liu, 2003: Relationship between the Tibetan Plateau heating and East Asian summer monsoon rainfall. Geophys. Res. Lett., 30, 2066, https://doi.org/ 10.1029/2003GL017909.

Jiang, X., and M. Ting, 2017: A dipole pattern of summertime rainfall across the Indian subcontinent and the Tibetan Plateau. J. Climate, 30, 9607-9620, https://doi.org/10.1175/ JCLI-D-16-0914.1.

— effect on interannual variability across the Indian subcontinent and the Tibetan Plateau. J. Climate, 32, 2227-2245, https://doi.org/10.1175/JCLI-D-18-0319.1.

_- S. Yang, Y. Li, Z. Ke, J. Li, and H. Hu, 2013a: Dominant modes of wintertime upper-tropospheric temperature variations over Asia and links to surface climate. J. Climate, 26, 9043-9060, https://doi.org/10.1175/JCLI-D-12-00774.1.

,$--\longrightarrow$, A. Kumar, X. Liu, Z. Zuo, and B. Jha, 2013b: Seasonal-to-interannual prediction of the Asian summer monsoon in the NCEP Climate Forecast System version 2. J. Climate, 26, 3708-3727, https://doi.org/10.1175/JCLI-D-1200437.1.

— , Y. Li, S. Yang, K. Yang, and J. Chen, 2016: Interannual variation of summer atmospheric heat source over the Tibetan Plateau and the role of convection around the western Maritime Continent. J. Climate, 29, 121-138, https://doi.org/ 10.1175/JCLI-D-15-0181.1.

Kitoh, A., 2004: Effects of mountain uplift on East Asian summer climate investigated by a coupled atmosphere-ocean GCM. J. Climate, 17, 783-802, https://doi.org/10.1175/1520-0442(2004) 017<0783:EOMUOE $>2.0 . C O ; 2$.

- H. Endo, K. Krishna Kumar, I. F. A. Cavalcanti, P. Goswami, and T. Zhou, 2013: Monsoons in a changing world: A regional perspective in a global context. J. Geophys. Res., 118, 30533065, https://doi.org/10.1002/jgrd.50258.

Lau, K.-M., and S. Yang, 1996: Seasonal cycle, abrupt transition, and intraseasonal variability associated with the Asian summer monsoon in the GLA GCM. J. Climate, 9, 965-985, https://doi.org/10.1175/1520-0442(1996)009<0965: SVATAI $>2.0 . \mathrm{CO} ; 2$.

_- K.-M. Kim, and S. Yang, 2000: Dynamical and boundary forcing characteristics of regional components of the Asian summer monsoon. J. Climate, 13, 2461-2482, https:// doi.org/10.1175/1520-0442(2000)013<2461:DABFCO > 2.0.CO;2.

Li, L., S. Yang, X. Zhu, Z. Wang, and H. Tang, 2010: Evidence of warming and wetting climate over the Qinghai-Tibet Plateau. Arct. Antarct. Alp. Res., 42, 449-457, https://doi.org/10.1657/ 1938-4246-42.4.449.

Li, Q., M. Zhao, S. Yang, X. Shen, Q. Ding, and Z. Liu, 2021: A zonally-oriented teleconnection pattern induced by heating of the western Tibetan Plateau in boreal summer. Climate Dyn., https://doi.org/10.1007/s00382-021-05841-6, in press..

Liu, X. D., and M. Yanai, 2001: Relationship between the Indian monsoon rainfall and the tropospheric temperature over the Eurasian continent. Quart. J. Roy. Meteor. Soc., 127, 909-937, https://doi.org/10.1002/qj.49712757311.

Liu, Y., Q. Bao, A. Duan, and G. Wu, 2007: Recent progress in the impact of the Tibetan Plateau on climate in China. Adv. Atmos. Sci., 24, 1060-1076, https://doi.org/10.1007/s00376-007-1060-3.

_- M. Lu, H. Yang, A. Duan, B. He, S. Yang, and G. Wu, 2020: Land-atmosphere-ocean coupling associated with the Tibetan Plateau and its climate impacts. Natl. Sci. Rev., 7, 534-552, https://doi.org/10.1093/nsr/nwaa011.

Lu, J., and M. Cai, 2009: A new framework for isolating individual feedback processes in coupled general circulation climate models. Part I: Formulation. Climate Dyn., 32, 873-885, https://doi.org/10.1007/s00382-008-0425-3.

Lu, M., S. Yang, Z. Li, B. He, S. He, and Z. Wang, 2018: Possible effect of the Tibetan Plateau on the "upstream" climate over West Asia, North Africa, South Europe and the North Atlantic. Climate Dyn., 51, 1485-1498, https://doi.org/10.1007/s00382017-3966-5.

Luo, H., and M. Yanai, 1983: The large-scale circulation and heat sources over the Tibetan Plateau and surrounding areas during the early summer of 1979: Part I: Precipitation and kinematic analyses. Mon. Wea. Rev., 111, 922-944, https://doi.org/ 10.1175/1520-0493(1983)111<0922:TLSCAH > 2.0.CO;2.

— over the Tibetan Plateau and surrounding areas during the early summer of 1979: Part II: Heat and moisture budgets. Mon. Wea. Rev., 112, 966-989, https://doi.org/10.1175/15200493(1984)112<0966:TLSCAH>2.0.CO;2.

Ma, D., W. Boos, and Z.-M. Kuang, 2014: Effects of orography and surface heat fluxes on the South Asian summer monsoon. J. Climate, 27, 6647-6659, https://doi.org/10.1175/JCLI-D-1400138.1.

Nan, S., P. Zhao, S. Yang, and J. Chen, 2009: Springtime tropospheric temperature over the Tibetan Plateau and evolutions of the tropical Pacific SST. J. Geophys. Res., 114, D10104, https://doi.org/10.1029/2008JD011559.

Neale, R. B., J. Richter, S. Park, P. H. Lauritzen, S. J. Vavrus, P. J. Rasch, and M. Zhang, 2013: The mean climate of the Community Atmosphere Model (CAM4) in forced SST and fully coupled experiments. J. Climate, 26, 5150-5168, https:// doi.org/10.1175/JCLI-D-12-00236.1.

Rodwell, M. J., and B. J. Hoskins, 1996: Monsoons and the dynamics of deserts. Quart. J. Roy. Meteor. Soc., 122, 1385-1404, https://doi.org/10.1002/qj.49712253408.

Song, Y., P. J. Webster, and D. Min, 1992: Longitudinal heating gradient: Another possible factor influencing the intensity of the Asian summer monsoon circulation. Adv. Atmos. Sci., 9, 397-410, https://doi.org/10.1007/BF02677073.

Tao, S., and L. Chen, 1987: A review of recent research on the East Asian summer monsoon in China. Monsoon Meteorology, C.-P. Chang and T. N. Krishnamurti, Eds., Oxford University Press, 60-92.

Ueda, H., and T. Yasunari, 1998: Role of warming over the Tibetan Plateau in early onset of the summer monsoon over the Bay of Bengal and the South China Sea. J. Meteor. Soc. Japan, 76, 1-12, https://doi.org/10.2151/jmsj1965.76.1_1.

Wang, B., and Z. Fan, 1999: Choice of South Asian summer monsoon indices. Bull. Amer. Meteor. Soc., 80, 629-638, https://doi.org/ 10.1175/1520-0477(1999)080<0629:COSASM>2.0.CO;2. 
_, R. Wu, and K.-M. Lau, 2001: Interannual variability of Asian summer monsoon: Contrast between the Indian and western North Pacific-East Asian monsoons. J. Climate, 14, 4073-4090, https://doi.org/10.1175/1520-0442(2001)014<4073:IVOTAS> 2.0.CO;2.

- Q. Bao, B. Hoskins, G. Wu, and Y. Liu, 2008a: Tibetan Plateau warming and precipitation changes in East Asia. Geophys. Res. Lett., 35, L14702, https://doi.org/10.1029/2008GL034330.

— Z. Zu, J. Li, J. Liu, C.-P. Chang, Y. Ding, and G. Wu, 2008b: How to measure the strength of the East Asian summer monsoon. J. Climate, 21, 4449-4463, https://doi.org/10.1175/ 2008JCLI2183.1.

Wang, H. J., 2002: Instability of the East Asian summer monsoonENSO relations. Adv. Atmos. Sci., 19 (1), 1-11, https://doi.org/ 10.1007/s00376-002-0029-5.

Wang, Z., A. Duan, and G. Wu, 2014: Time-lagged impact of spring sensible heat over the Tibetan Plateau on the summer rainfall anomaly in East China: Case studies using the WRF model. Climate Dyn., 42, 2885-2898, https://doi.org/10.1007/s00382013-1800-2.

,,-- M. Li, and B. He, 2016: Influences of thermal forcing over the slope/platform of the Tibetan Plateau on Asian summer monsoon: Numerical studies with WRF model. Chin. J. Geophys., 59, 474-487, https://doi.org/10.1002/cjg2.30007.

Webster, P. J., 1983: Mechanisms of monsoon low-frequency variability: Surface hydrological effects. J. Atmos. Sci., 40, 2110-2124, https://doi.org/10.1175/1520-0469(1983)040<2110: MOMLFV $>2.0 . \mathrm{CO} ; 2$.

— active systems. Quart. J. Roy. Meteor. Soc., 118, 877-926, https://doi.org/10.1002/qj.49711850705.

—, V. O. Magaña, T. N. Palmer, T. A. Tomas, M. Yanai, and T. Yasunari, 1998: Monsoons: Processes, predictability, and prospects for prediction. J. Geophys. Res., 103, 14 451-14 510, https://doi.org/10.1029/97JC02719.

Wu, G., and Y. S. Zhang, 1998: Tibetan Plateau forcing and the timing of the monsoon onset over South Asia and the South China Sea. Mon. Wea. Rev., 126, 913-927, https://doi.org/10.1175/ 1520-0493(1998)126<0913:TPFATT >2.0.CO;2.

—_ W. P. Li, H. Guo, H. Liu, J. S. Xue, and Z. Z. Wang, 1997: The sensible heat driven air-pump over the Tibetan Plateau and the Asian summer monsoon. Collection in the Memory of Dr. Zhao Jiuzhang, D. Ye, Ed., Chinese Science Press, 116-126.

—_, and Coauthors, 2007: The influence of mechanical and thermal forcing by the Tibetan Plateau on Asian climate. J. Hydrometeor., 8, 770-789, https://doi.org/10.1175/JHM609.1. , Y. Liu, X. Zhu, W. Li, R. Ren, A. Duan, and X. Liang, 2009: Multi-scale forcing and the formation of subtropical desert and monsoon. Ann. Geophys., 27, 3631-3644, https://doi.org/ 10.5194/angeo-27-3631-2009.
,-- B. He, Q. Bao, A. Duan, and F. Jin, 2012: Thermal controls on the Asian summer monsoon. Sci. Rep., 2, 404, https://doi.org/10.1038/srep00404.

- , and Coauthors, 2015: Tibetan Plateau climate dynamics: Recent research progress and outlook. Natl. Sci. Rev., 2, 100116, https://doi.org/10.1093/nsr/nwu045.

-, H. Zhuo, Z. Wang, and Y. Liu, 2016: Two types of summertime heating over the Asian large-scale orography and excitation of potential vorticity forcing over Tibetan Plateau. Sci. China Earth Sci., 59, 1996-2008, https://doi.org/10.1007/ s11430-016-5328-2.

Wu, Y., S. Yang, X. Hu, and W. Wei, 2020: Process-based attribution of long-term surface warming over the Tibetan Plateau. Int. J. Climatol., 40, 6410-6422, https://doi.org/10.1002/joc.6589.

Yang, S., Z. Zhang, V. E. Kousky, R. W. Higgins, S.-H. Yoo, J. Liang, and Y. Fan, 2008: Simulations and seasonal prediction of the Asian summer monsoon in the NCEP Climate Forecast System. J. Climate, 21, 3755-3775, https://doi.org/ 10.1175/2008JCLI1961.1.

Ye, D., and G. Wu, 1998: The role of the heat source of the Tibetan Plateau in the general circulation. Meteor. Atmos. Phys., 67, 181-198, https://doi.org/10.1007/BF01277509.

Yeh, T. C., S. W. Luo, and P.-C. Chu, 1957: The wind structure and heat balance in the lower troposphere over Tibetan Plateau and its surrounding. Acta Meteor. Sin., 28, 108-121, https:// doi.org/10.11676/qxxb1957.010.

Yoo, S.-H., S. Yang, and C.-H. Ho, 2006: Variability of the Indian Ocean sea surface temperature and its impacts on AsianAustralian monsoon climate. J. Geophys. Res., 111, D03108, https://doi.org/10.1029/2005JD006001.

Zhao, P., S. Yang, and R. Yu, 2010: Long-term changes in rainfall over eastern China and large-scale atmospheric circulation associated with recent global warming. J. Climate, 23, 15441562, https://doi.org/10.1175/2009JCLI2660.1.

,,-- H. Wang, and Q. Zhang, 2011: Interdecadal relationships between the Asian-Pacific Oscillation and summer climate anomalies over Asia, North Pacific, and North America during a recent 100 years. J. Climate, 24, 4793-4799, https:// doi.org/10.1175/JCLI-D-11-00054.1.

- _ _ Z Z. Wen, and R. Wu, 2012: Asian origin of the interannual variations of summer climate over the extratropical Atlantic Ocean. J. Climate, 25, 6594-6609, https://doi.org/ 10.1175/JCLI-D-11-00617.1.

Zuo, Z., S. Yang, A. Kumar, R. Zhang, Y. Xue, and B. Jha, 2012: Role of thermal condition over Asia in the weakening Asian summer monsoon under global warming background. J. Climate, 25, 3431-3436, https://doi.org/10.1175/JCLI-D-11-00742.1.

- _ _ R. R. Zhang, P. Jiang, L. Zhang, and F. Wang, 2013: Longterm variations of broad-scale Asian summer monsoon circulation and possible causes. J. Climate, 26, 8947-8961, https:// doi.org/10.1175/JCLI-D-12-00691.1. 